\title{
TIL 1383I T Cell Receptor-Transduced Autologous T Cells
}

National Cancer Institute

\section{Source}

National Cancer Institute. TIL 13831 T Cell Receptor-Transduced Autologous T Cells. NCI

Thesaurus. Code C101787.

Autologous peripheral blood lymphocytes-derived T cells transduced with a retroviral encoding TIL 1383I, a T cell receptor (TCR) specific for melanoma antigen tyrosinase, with potential immunostimulating and antineoplastic activity. After transduction, expansion in culture, and reintroduction into the patient, TIL 1383I TCR-transduced autologous T cells bind to tumor cells expressing tyrosinase, which may induce cytokine expression, activation and proliferation of T-cells, and a specific cytotoxic T-lymphocyte (CTL) response ag ainst tyrosinase-expressing tumor cells. TIL 1383I TCR originated from a melanoma patient's CD4+ tumor-infiltrating lymphocytes and is reactive against a class I MHC (HLA-A2)-restricted epitope (368-376) of tyrosinase. 